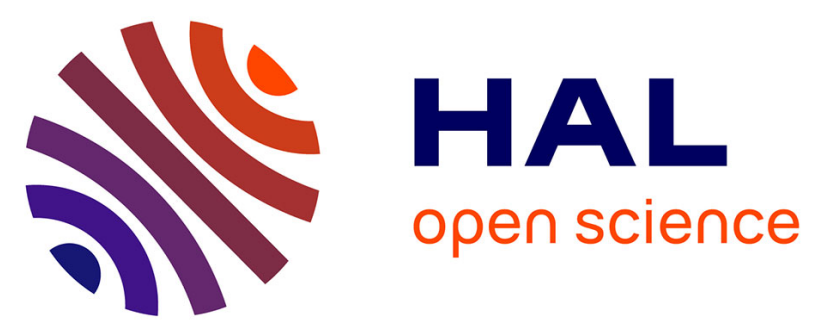

\title{
Does selenium fortification of kale and kohlrabi sprouts change significantly their biochemical and cytotoxic properties?
}

\author{
Pawel Zagrodzki, Pawel Paśko, Agnieszka Galanty, Malgorzata \\ Tyszka-Czochara, Renata Wietecha-Posluszny, Pol Salvans Rubió, Henryk \\ Bartoń, Ewelina Prochownik, Bożena Muszyńska, Katarzyna Sulkowska-Ziaja, \\ et al.
}

\section{- To cite this version:}

Pawel Zagrodzki, Pawel Paśko, Agnieszka Galanty, Malgorzata Tyszka-Czochara, Renata WietechaPosluszny, et al.. Does selenium fortification of kale and kohlrabi sprouts change significantly their biochemical and cytotoxic properties?. Journal of Trace Elements in Medicine and Biology, 2020, 59, pp.126466. 10.1016/j.jtemb.2020.126466 . hal-03133477

\author{
HAL Id: hal-03133477 \\ https://hal.science/hal-03133477
}

Submitted on 17 Feb 2021

HAL is a multi-disciplinary open access archive for the deposit and dissemination of scientific research documents, whether they are published or not. The documents may come from teaching and research institutions in France or abroad, or from public or private research centers.
L'archive ouverte pluridisciplinaire HAL, est destinée au dépôt et à la diffusion de documents scientifiques de niveau recherche, publiés ou non, émanant des établissements d'enseignement et de recherche français ou étrangers, des laboratoires publics ou privés. 


\section{Does selenium fortification of kale and kohlrabi sprouts change significantly their biochemical and cytotoxic properties?}

Paweł Zagrodzki ${ }^{a}$ Paweł Paśko ${ }^{a}$ Agnieszka Galanty ${ }^{b}$ MałgorzataTyszka-Czochara ${ }^{a}$ Renata WietechaPosłuszny ${ }^{\mathrm{c}}$ Pol Salvans Rubió ${ }^{\mathrm{d}}$ Henryk Bartoń ${ }^{\mathrm{a}}$ Ewelina Prochownik ${ }^{\mathrm{a}}$ Bożena Muszyńska ${ }^{\mathrm{e}}$ Katarzyna Sułkowska-Ziaja ${ }^{\mathrm{e}}$ Katarzyna Bierła ${ }^{\mathrm{f}}$ Ryszard Łobiński ${ }^{\mathrm{fg}}$ Joanna Szpunar $^{\mathrm{f}}$ Shela Gorinstein $^{\mathrm{h}}$

${ }^{\mathrm{a}}$ Department of Food Chemistry and Nutrition, Faculty of Pharmacy, Medical College, Jagiellonian University, Medyczna 9, 30-688 Kraków, Poland

${ }^{\mathrm{b}}$ Department of Pharmacognosy, Faculty of Pharmacy, Medical College, Jagiellonian University, Medyczna 9, 30-688 Kraków, Poland

'Department of Analytical Chemistry, Faculty of Chemistry, Jagiellonian University, Gronostajowa 2, 30387 Kraków, Poland

${ }^{d}$ Faculty of Pharmacy and Food Science University of Barcelona, Diagonal Campus Joan XXIII 27-31, 08028 Barcelona, Spain

${ }^{\mathrm{e}}$ Department of Pharmaceutical Botany, Faculty of Pharmacy, Medical College, Jagiellonian University, Medyczna 9, 30-688 Kraków, Poland

${ }^{\text {f}}$ Universite de Pau et des Pays de l'Adour, E2S UPPA, CNRS, IPREM UMR 5254, Hélioparc, 64053 Pau, France

${ }^{8}$ IM Sechenov First Moscow State Medical University (Sechenov University), 119146 Moscow, Russia

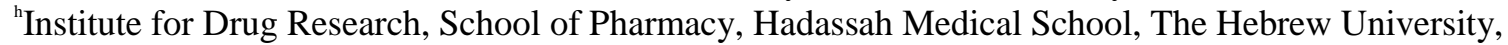
91120 Jerusalem, Israel

\section{Highlights}

- Biochemical and cytotoxic properties of Brassica Se-fortified sprouts were examined.

- About $10 \%$ of selenium was incorporated into the sprouts as selenomethionine.

- Selenium differently stimulated the production of phenolic acids in the sprouts.

- Cytotoxic potency of sprouts regardless the Se fortification was observed.

- Se-enriched sprouts are attractive candidates for functional food.

\section{Abstract}

\section{Background}

The sprouts of Brassica vegetables are known from their nutritional and chemopreventive values. Moreover, sprouts fortification with some trace elements, like selenium, may increase their importance in human diet. Thus, the aim of our study was to examine if selenium enrichment of kale and kohlrabi sprouts may 
influence their biochemical properties (phenolic acids and L-tryptophan content, antioxidant potential) or cytotoxic activity. Additional aim of the study was to evaluate the profile of selenium compounds and to describe the multidimensional interactions between the mentioned parameters.

\section{Methods}

Selenium content in the sprouts was evaluated by double-channel atomic fluorescence spectrometer AFS-230 with the flow hydride-generation system. Separation of selenium species in water soluble fraction was performed by sizeexclusion LC-ICP-MS. The identification and quantification of phenolic acids and L-tryptophan was performed by HPLC. For antioxidant activity DPPH and FRAP methods were used. Cytotoxic activity of the sprouts extracts on a panel of human metastatic carcinoma cells was evaluated by MTT test.

\section{Results}

Selenium content in the fortified sprouts was several orders of magnitude higher than in the unfortified ones. Only small percentage of supplemented selenium (ca. 10\%) was incorporated into the sprouts as seleno-L-methionine, while the other detected selenium species remained unidentified. Selenium fortification differently stimulated the production of phenolic acids (sinapic, chlorogenic, isochlorogenic and caffeic acid) in the tested sprouts, depending on the particular species, selenium dose and the investigated compound. PCA analysis revealed strong correlation between antioxidant parameters and phenolic acids and L-tryptophan, while Se correlated only with caffeic acid. The sprouts extracts ( $\geq 1 \mathrm{mg} / \mathrm{mL}$ ) showed cytotoxic potency to all the studied cancer cell lines (SW480, SW620, HepG2, SiHa), regardless the selenium supplementation.

\section{Conclusion}

Se-fortified kale and kohlrabi sprouts are good candidates for functional food ingredients. Moreover, these results indicate that the sprouts enriched with sodium selenite show higher nutritional value, without significant changes in their cytotoxic activity.

- Previous article in issue

- Next article in issue 


\section{Keywords}

Selenium

Sprouts

Phenolic acids

Speciation analysis

Cytotoxic activity

\section{Introduction}

The sprouts of various vegetables from Brassica family have not only appreciable nutritional values, but are also cheap and easy to grow. They are rich in polyphenols, glucosinolates and vitamins, but also a number of trace elements, which support plant growth rate and exert beneficial influence on human health, when consumed [1]. Kale (Brassica oleracea L. var. sabellica L.), together with its sprouts, are known from their positive effect on cancer and cardiovascular diseases prevention $[2, \underline{3}]$. Kohlrabi (Brassica oleracea convar. acephala var. gongylodes) is one of the underestimated but perspective Brassica vegetable, with only few data on the properties of its sprouts [4].

The sprouts, as extra source of trace elements, may play advantageous role for people, particularly those suffering from malnutrition or living in the areas with some elements deficiency (e.g. iodine, zinc). The problem concerns also the deficiency of selenium (Se), an important trace element [ $\underline{5}$ ]. Selenium fortified sprouts may deliver some benefits. Except from being the additional source of selenium, the enriched sprouts have greater antioxidant, anti-inflammatory and anti-tumour properties [1]. The selenium accumulation in plant organism can cause its growth by stimulating the seeds germination and thus promoting the production of secondary metabolites, which trigger multiple biological effects [1, $\underline{6}]$. Avila et al. [] ] indicated Brassica crops as a special group of plants with high ability to synthesize and accumulate monomethylated forms of selenium, such as Se-methylselenocysteine (SeMSCys). It is also suggested that selenium fortification of Brassica seeds may increase their chemopreventive activity, besides being a dietary source of a number of other bioactive compounds $[\underline{8}, \underline{9}]$. In addition, it is worth to mention that the extra amount of selenium protects plant organisms against the influence of drought [10], cold [11], UV radiation [12], heavy metals and salts [1] $]$. 
Although the methods for enhancing Se levels in animal products (eggs, milk, meat) are well documented, the information on Se fortification of plants is still incomplete. Thus, the aim of our work was to examine biochemical properties of kale and kohlrabi sprouts - new example of plant functional foods, supplemented with different doses of selenium and to investigate the multidimensional interactions between the parameters studied. The different biochemical properties of Se-fortified new Brassica sprouts, being the subject of the present study, have not been investigated previously. Another objective of the study was to determine and compare cytotoxic activity of Se-fortified or unfortified sprouts. As the therapeutic window of selenium is rather narrow [14] we also tried to carefully select the level of supplementation in new sprouts, which may be implemented to the daily menu in the future. Additionally, speciation analysis was applied to evaluate the profile of selenium compounds.

\section{Material and methods}

\subsection{Plant material and growth conditions for sprouts}

Kale seeds (Brassica oleracea L. var. sabellica L.) were collected from the plants harvested in north-west Poland in 2016. Voucher specimen was deposited in the Department of Food Chemistry and Nutrition, Faculty of Pharmacy, Jagiellonian University Medical College (No\#BOS/PP/PL1044). Kohlrabi seeds (Brassica oleracea convar. acephala var. gongylodes) were collected from the plants harvested in north-west Poland in 2012. Voucher specimen was deposited in the Legutko Seed Testing Laboratory (LE11/1135/12) and also in the Department of Food Chemistry and Nutrition, Faculty of Pharmacy, Jagiellonian University Medical College (No\#BOAG/PP/PL 1043).

The seeds were immersed in commercially available mineral water (controls) or in the same water containing three different selenium concentrations $(10 \mathrm{mg} / \mathrm{L}, 15 \mathrm{mg} / \mathrm{L}$, $30 \mathrm{mg} / \mathrm{L}$; selenium as sodium selenite) for $3 \mathrm{~h}$. Then the seeds were grown for 6 days after seeding in EQMM Easy Green Microfarm in temperature of $24 \pm 2{ }^{\circ} \mathrm{C}$, at natural light conditions, being watered 3 times a day with mineral water or Se-supplemented water (selenium concentrations as above).

The extracts for the evaluation of phenolic acids content, antioxidant parameters and for cellular studies were prepared according to the protocols described in details in our previous paper [15]. 


\subsection{Selenium content and speciation analysis}

Selenium content in the sprouts was evaluated by means of the double-channel atomic fluorescence spectrometer AFS-230 with the flow hydride-generation system (Haiguang Instrument, Beijing, China), as described earlier [15, 16].

Speciation analysis was applied to kale and kohlrabi sprouts grown for 6 days and watered either with mineral water or with selenium solution in mineral water (intermediate concentration, i.e. $15 \mathrm{mg} / \mathrm{L}$ ). Digi-Prep system from SCP Science (Quebec, Canada) was used for digestion of samples. Two types of centrifuge: Jouan CR3i Model (Thermo Fisher Scientific, Waltham, MS) and a model 5415R 72 (Eppendorf, Hamburg, Germany) were used for various sample volumes. Separation of selenium species present in water soluble fraction was performed by means of size-exclusion LC-ICP-MS [17]. For incubation of the samples an ultrasonic bath Branson 2510 from Emerson (Danbury, CT), and a thermostatic shaking water bath OLS 200 from Grant (Cambridge, UK) were used. $\mathrm{pH}$ was adjusted with $\mathrm{pH}-213 \mathrm{pH}$ meter from Hanna Instruments (Woonsocket, RI). The HPLC system used was: Agilent 1200 HPLC from Agilent Technologies (Tokyo, Japan), with the chromatographic columns size-exclusion Superdex-75 $(10 \times 300 \mathrm{~mm} \times 13 \mu \mathrm{m})$ from GE Healthcare (Little Chalfont, UK) and anion exchange PRP x100 $(4.1 \times 250 \mathrm{~mm}$ x5 $\mu \mathrm{m}$ ) from Hamilton Robotics (Reno, NV).

\subsection{Water extraction and size-exclusion HPLC fractionation of selenium}

$5 \mathrm{~mL}$ of water was added to $0.2 \mathrm{~g}$ of each sample; the mixture was incubated in ultrasonic bath $(1 \mathrm{~h})$ and centrifuged. The supernatant was eluted from a size exclusion HPLC Superdex-75 column (exclusion limit of $100 \mathrm{kDa}$ and the optimal separation range of 3-70 $\mathrm{kDa}$ ) with $100 \mathrm{mM}$ ammonium acetate buffer ( $\mathrm{pH} 7.5)$ at a flow rate of $0.7 \mathrm{~mL} / \mathrm{min}$. Selenium isotopes: ${ }^{76} \mathrm{Se},{ }^{77} \mathrm{Se},{ }^{78} \mathrm{Se},{ }^{80} \mathrm{Se}$ and ${ }^{82} \mathrm{Se}$ were monitored by ICP-MS. The ICP mass spectrometer used was an Agilent 7700x (Agilent, Tokyo, Japan) equipped with a collision cell; hydrogen was used as a collision gas to remove interferences; the correctness of the Se isotopic pattern was verified daily before the analysis. The instrumental LOD was $10 \mathrm{ppt}$. The observed isotopic pattern matched the theoretical one which indicated the absence of interference.

\subsection{Selenomethionine and Se-methylselenocysteine determination}


$0.2 \mathrm{~g}$ of each sample was incubated with $5 \mathrm{~mL}$ of a protease solution $(20 \mathrm{mg}$ protease in $30 \mathrm{mM}$ TRIS buffer, $\mathrm{pH}$ 7.5). Three consecutive incubations $\left(17 \mathrm{~h}\right.$ at $\left.37^{\circ} \mathrm{C}\right)$ with fresh portions of the enzyme solution were carried out. After each incubation, the sample was centrifuged (10 min at $2500 \mathrm{rpm})$ and the supernatant was transferred to a separate vial to which $5 \mu \mathrm{L}$ of $\beta$-mercaptoethanol was added. The 3 supernatants were pooled together and analysed by anion-exchange chromatography (Hamilton PRP-X100 column) coupled to ICP-MS. Separation was performed using gradient elution with buffers A (20 mM acetic acid/10 mM triethylamine) and B (200 mM acetic acid/100 $\mathrm{mM}$ triethylamine) according to the following program: 0-5 min: $0 \%$ B, 5-30min: 0-100 \% B, 30-40 min: $100 \%$ B, 40-41: 100-0 \% B, 41-45 min: 0 \% B. The quantification was carried out using standard additions of SeMet and SeMetSeCys at three levels. The samples were analysed in duplicate. Analytical blanks and SELM-1 standard reference material certified for SeMet content (National Research Council Canada) were analysed in parallel. The observed isotopic pattern matched the theoretical one which indicated the absence of interference.

Analytical reagent grade chemicals and LC-MS grade solvents were purchased from Sigma-Aldrich (Saint Quentin Fallavier, France) unless stated otherwise. Ultra-pure water $(18 \mathrm{M} \Omega \mathrm{cm}$ ) obtained with a MiliQ system (Millipore, Bedford, MA) was used throughout. Hydrogen peroxide from Fisher Scientific (Hampton, NH) and nitric acid (INSTRA-ANALYZED) from Baker (Central Valley, PA) were used for sample digestion. Protease used was of proteomics grade. A standard solution of $1000 \mathrm{mg} / \mathrm{L}$ selenium was purchased from Plasma CAL standards (Teddington, UK). Standard stock solutions of SeMet and MetSeCys were prepared by dissolving powders obtained from Sigma Aldrich, and appropriately diluting with water.

\subsection{Identification and quantification of phenolic acids}

The identification and quantification of phenolic acids was performed by means of HPLC, as described previously [18], with Dionex HPLC system with PDA 100 UVVIS detector, Hypersil Gold (C-18) column $(5 \mu \mathrm{m}, 250 \times 4.6 \mathrm{~mm}$, Thermo EC) mobile phase $1 \%$ formic acid in water (A) and acetonitrile (B) in gradient mode 5$60 \% \mathrm{~B}$ in $60 \mathrm{~min}$, at a flow-rate of $1 \mathrm{~mL} / \mathrm{min}$. Identification of the compounds was done by comparing their retention time with those of the standards. Quantification of the predominant compounds was carried out by measuring the peak area with regards 
to the appropriate standard curve prepared for the range of standards concentrations from 0.0625 to $1 \mathrm{mg} / \mathrm{mL}$. All analyses were performed in triplicate and the mean value was expressed in $\mathrm{mg} / 100 \mathrm{~g}$ dry weight (d.w.).

\subsection{L-tryptophan determination}

For L-tryptophan determination, the samples ( $0.5 \mathrm{~g}$ each $)$ of air dried material were extracted with methanol as described previously [19]. The quantitative analysis of Ltryptophan were performed using a modified HPLC method [20]. Details of the parameters and conditions of chromatographic separation were reported previously [21]. Reference materials were from Sigma-Aldrich Co. Quantification was carried out based on the method of calibration curve.

\subsection{Antioxidant activity and total phenolic compounds determination}

In order to determine the antioxidant activity of the tested materials, the scavenging of 2,2-diphenyl-1-picrylhydrazyl (DPPH assay) was done according to BrandWilliams et al. method [22] with some modifications [23], while ferric reducing antioxidant power assay (FRAP) was conducted according to Benzie and Strain [24], with further modifications [23]. Total extractable polyphenols concentrations (TPC, considered also as Total Phenolic Compounds) were measured using FolinCiocalteau method with some modifications [ㄹ3]. For DPPH, FRAP, and TPC assays Synergy-2 (BioTek, USA) reader with syringe rapid dispensers was used.

\subsection{Cell cultures}

Cytotoxic activity was evaluated using a panel of human metastatic carcinoma cells of various tissue origin: SW 480 Duke's type B primary colorectal adenocarcinoma (ATCC, CCL-228); SW 620 Duke's type C colorectal adenocarcinoma, derived from lymph node as metastatic site (ATCC, CCL-227); HepG2 hepatocellular carcinoma (ATCC, HB-8065) and SiHa cervical carcinoma cells (ATCC, HTB-35). SW 480 and SW 620 cells were cultured in Dulbecco's Modified Eagle's Medium (DMEM; Lonza, USA), HepG2 and SiHa cell lines were maintained in Eagle's Minimum Essential Medium (EMEM; Lonza, USA) as described earlier [25]. All media were supplemented with $10 \%$ v/v FBS (Eurex Sp. z o.o., Poland) and antibiotic solution. The cells were grown in standard conditions $\left(37^{\circ} \mathrm{C}\right.$ in a humidified atmosphere of $5 \% \mathrm{CO}_{2}$ ). The morphology of cell culture was investigated by an inverted light 
microscope (Olympus IX-70 microscope with fluorescence, Olympus, Hamburg, Germany).

\subsection{Viability assay}

The effect of the sprouts towards human carcinoma cells was determined using MTT (3-[4,5-dimethylthiazol-2 yl]-2,5-diphenyl tetrazolium bromide) assay (SigmaAldrich, Germany). Briefly, $200 \mu \mathrm{L}$ of cell suspension was placed in 96-well microtiter plate for $24 \mathrm{~h}$. Then the medium in each well was replaced with a new one, containing also the adequate volume of a diluted stock solution of the tested extracts or the solvent, dimethylsulfoxide (DMSO). The cells cultured in the medium alone were positive control (100\% of viability). The range of the tested concentrations of the extracts was: $0.1 \mathrm{mg} / \mathrm{mL}-5 \mathrm{mg} / \mathrm{mL}$. After $24 \mathrm{~h}$ of incubation the medium was removed, MTT solution was added, the obtained formazan was dissolved in DMSO and the absorbance was measured at $550 \mathrm{~nm}$ (the reference wavelength was $690 \mathrm{~nm}$ ) using microplate reader [26].

\subsection{Statistical approach}

ANOVA analysis with post-hoc Tukey or least significant difference tests were applied. A probability level of $p<0.05$ was considered to be statistically significant. Principal Component Analysis model (PCA) was used in order to describe the correlation structure between the parameters and to reveal possible differences between the individual samples of the sprouts. Correlation weights (which express the strength of bivariate associations) for the pairs of the parameters in PCA model were calculated using the software delivered by MP System Co. (Chrzanów, Poland).The parameters with large weights $(>0.3)$ in PCA model were assumed to be correlated.The Pearson correlation coefficients for pairs of the parameters were also calculated to compare the results obtained by different statistical methodologies. Statistical analyses were carried out using packages: STATISTICA v. 12 (Statsoft, Tulsa, OK, USA) and SIMCA-P v.9 (Umetrics, Umeå, Sweden).

\section{Results}

Selenium exposure did not cause any apparent sprouts growth inhibition even at exposure levels of $30 \mathrm{mg} \mathrm{Se} / \mathrm{L}$. Selenium content in the sprouts was shown in Fig. 1. Water soluble selenium fraction was $35.1 \%$ and $22.2 \%$ of total selenium in kale and 
kohlrabi fortified sprouts, respectively. Selenium as selenomethionine (SeMet) was present in both kale $(7.3 \pm 0.6 \%$ of total Se) and kohlrabi (11.6 $\pm 0.6 \%$ of total Se) sprouts. The results of the separation of selenium species present in water soluble fraction in kohlrabi and kale sprouts were illustrated in Fig. 2. The additional experiment carried out by the HPLC technique with higher resolution power (hypercarb HPLC column) confirmed the presence of additional three low molecular weight ( $<1000 \mathrm{Da}$ ) selenium species (one major and two minor) in the investigated samples (Fig. 2C and D), which were neither SeMet, nor Se (IV) and Se (VI).

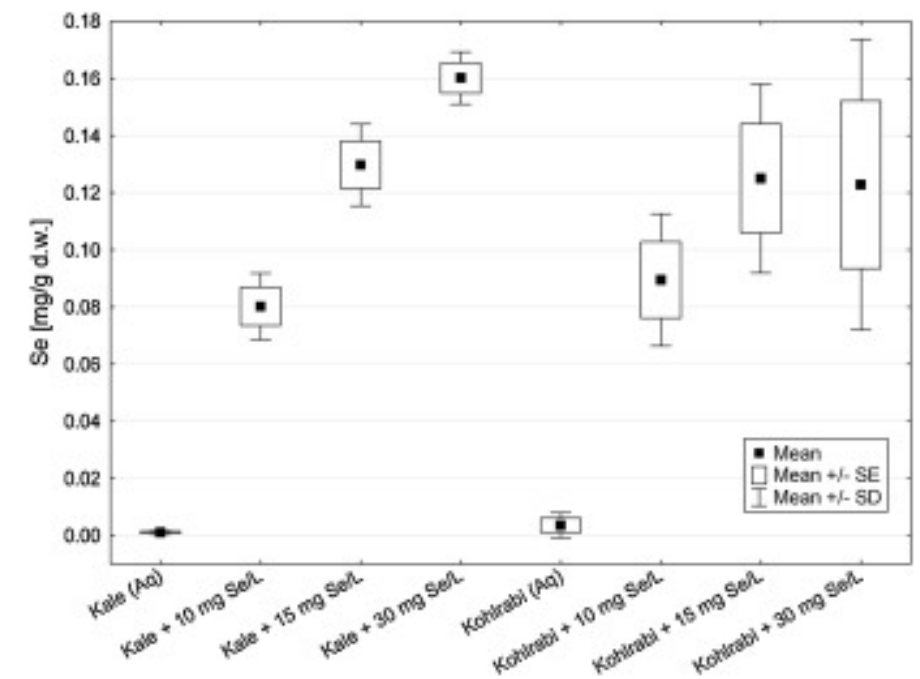

Fig. 1. Selenium concentration in kale and kohlrabi sprouts.
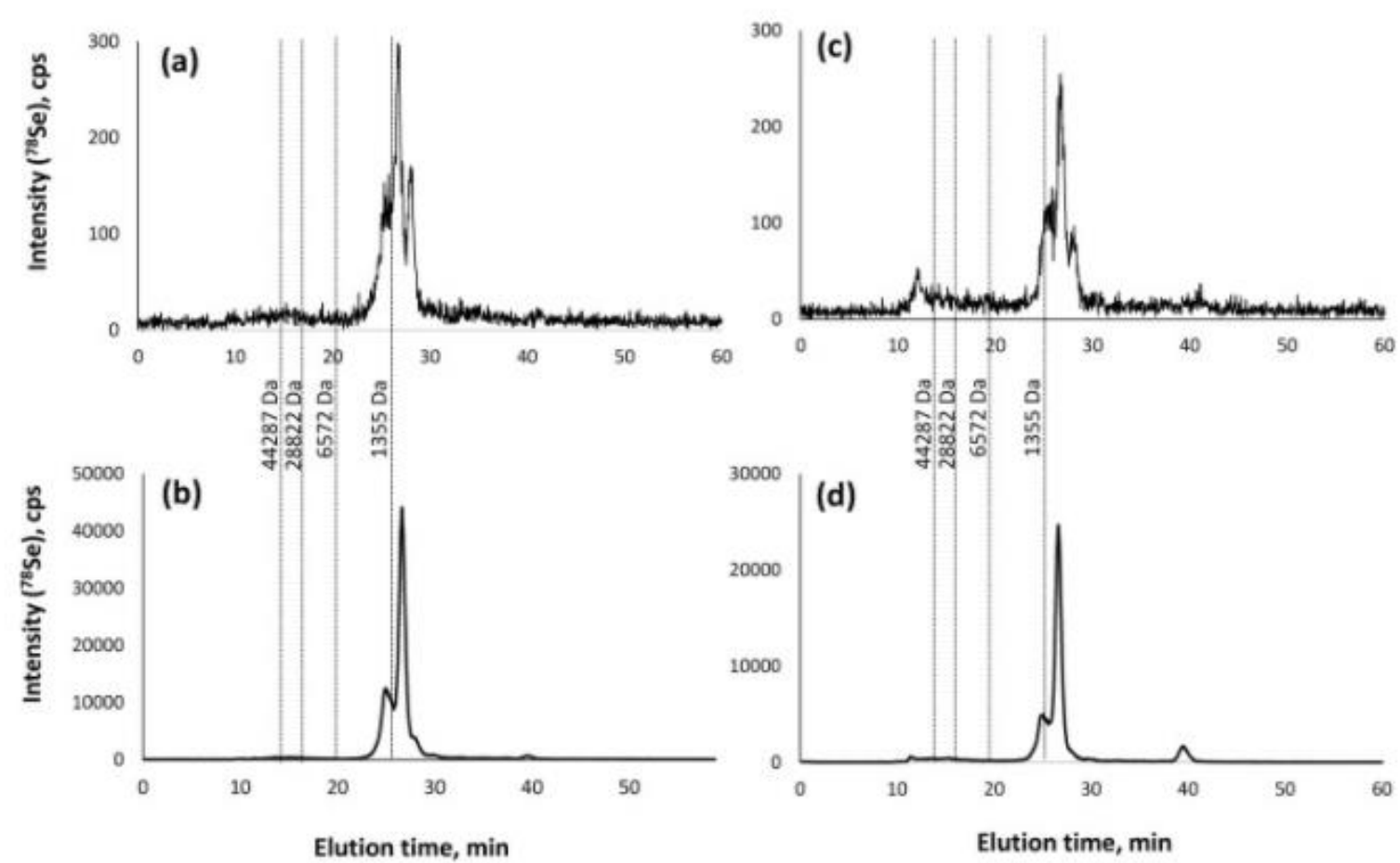
Fig. 2. Size-exclusion-ICP-MS chromatograms of selenium species present in the water soluble fraction of sprouts obtained using a Superdex-75 column with $100 \mathrm{mM}$ ammonium acetate buffer ( $\mathrm{pH} 7.5$ ) elution at a flow rate of $0.7 \mathrm{~mL} / \mathrm{min},{ }^{78} \mathrm{Se}$ ICP MS signal is shown; upper part - unfortified (a) kale and (b) kohlrabi sprouts, lower part Se fortified (15 mg/L) (c) kale and (d) kohlrabi sprouts. Dashed lines show elution times of molecular weight standards used for the calibration of the column used.

Anion-exchange HPLC-ICP MS chromatograms obtained for aqueous extracts and proteolytic digests of kale and kohlrabi fortified sprouts were shown on Fig. 3. Selenomethionine concentrations in aqueous extracts of both plants were on the same level of $0.80 \pm 0.10 \mu \mathrm{g} / \mathrm{g}$, while in proteolytic digests they were $9.8 \pm 1.2$ and $9.5 \pm 1.0 \mu \mathrm{g} / \mathrm{g}$ for kale and kolhrabi, respectively. The Se-methylselenocysteine concentrations in aqueous extracts were equal $0.60 \pm 0.10 \mu \mathrm{g} / \mathrm{g}$ and $0.83 \pm 0.20 \mu \mathrm{g} / \mathrm{g}$ for kale and kohlrabi sprouts, respectively. The corresponding values of SeMetSeCys concentrations in proteolytic digests were $0.72 \pm 0.09$ and $1.1 \pm 0.2$, respectively. The content of phenolic acids, namely sinapic, chlorogenic, isochlorogenic, caffeic acid, and L-tryptophan were shown in Fig. 4, Fig. 5, respectively, while total phenolic content and antioxidant parameters in the sprouts (DPPH, FRAP) were summarized in Fig. 6.
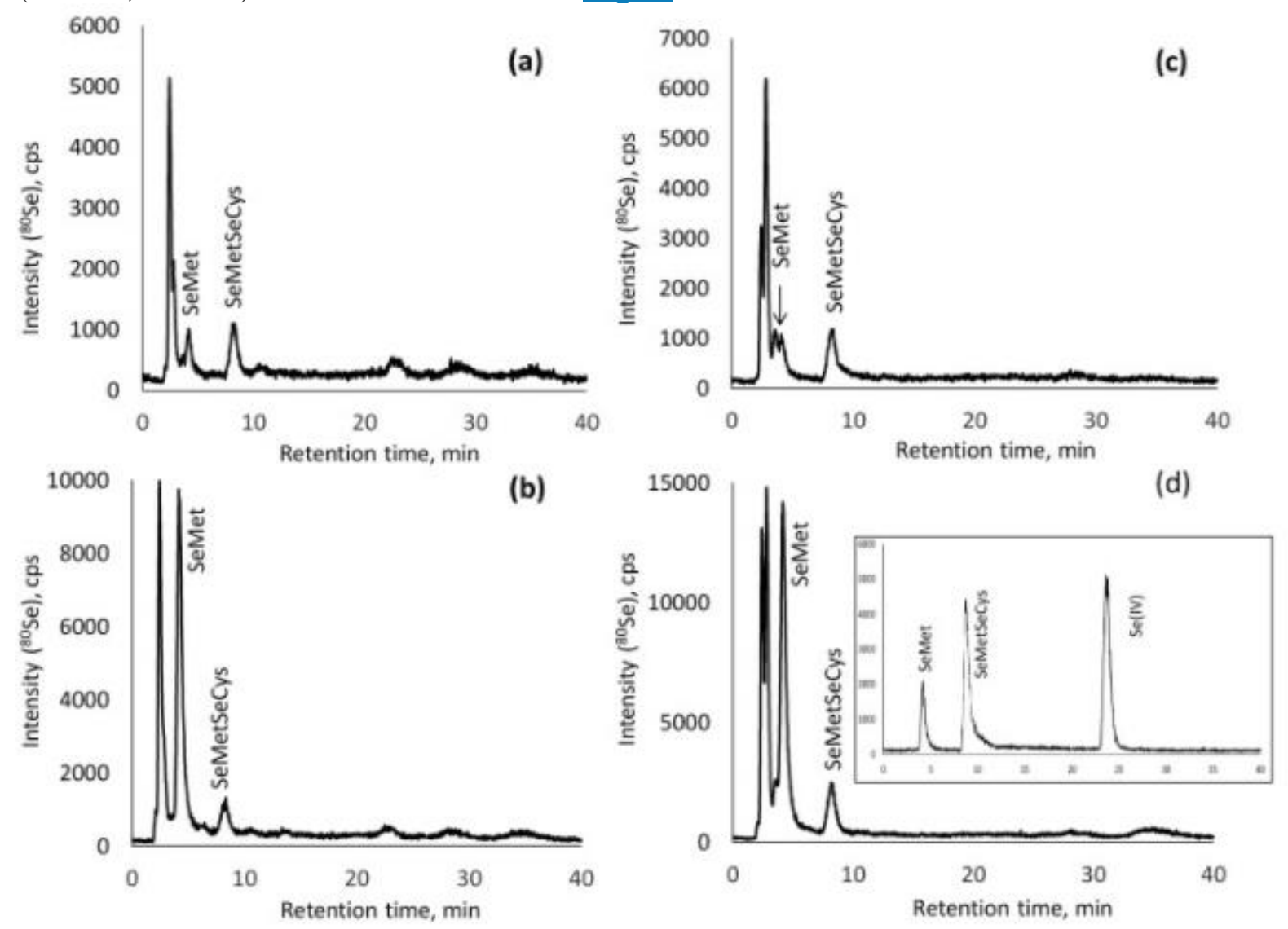
Fig. 3. Anion-exchange HPLC-ICP MS chromatograms obtained for aqueous extracts $(a, c)$ and proteolytic digestates (b, d) of kale (a, b) and kolhrabi (c, d) sprouts. A chromatogram of standards is presented in the inset.

A

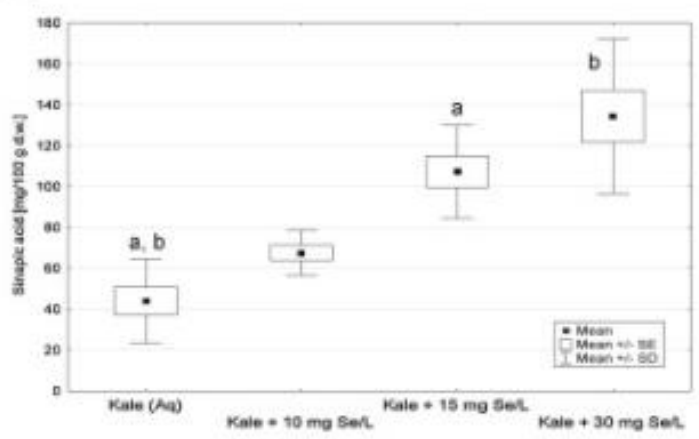

C

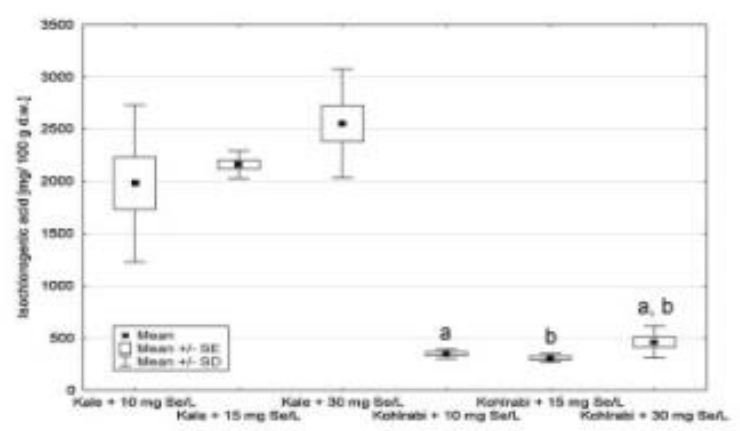

B

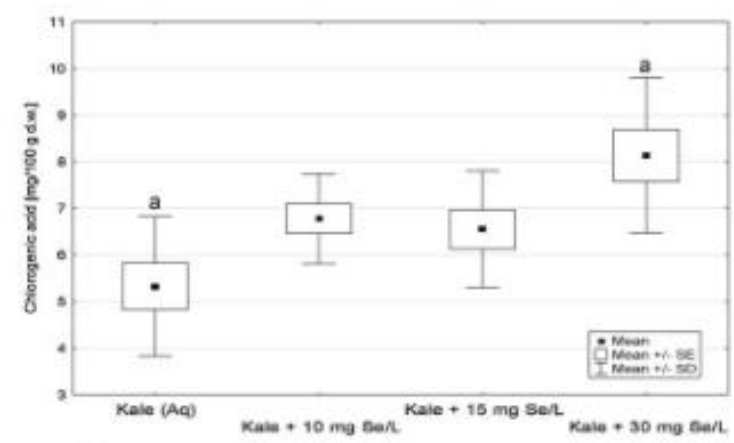

D

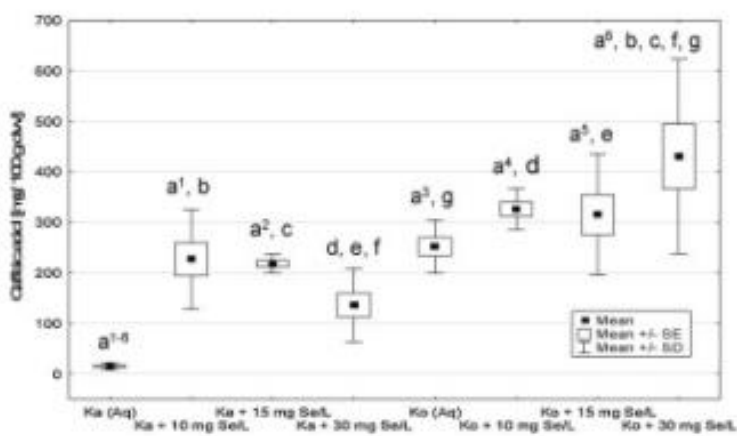

Fig. 4. Phenolic acids concentrations in kale and kohlrabi sprouts (the groups marked with the same index differed significantly). A: Sinapic acid; B: Chlorogenic acid; C: Isochlorogenic acid (because of apparent difference between kale and kohlrabi sprouts, statistical tests were applied separately for this acid); D: Caffeic acid (meaning of abbreviations $\mathrm{Ka}$ - kale, Ko-kohlrabi).

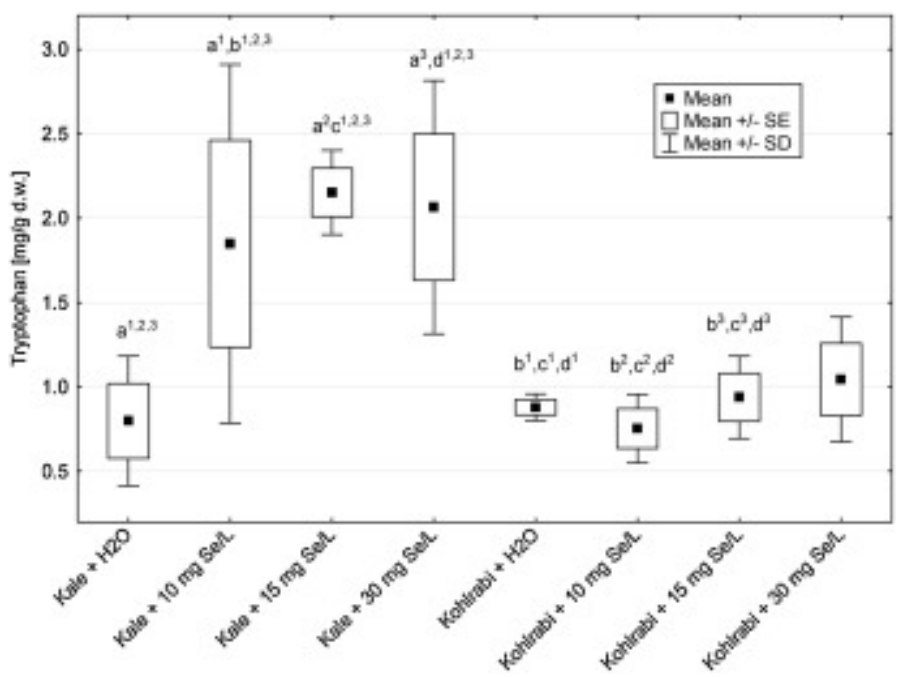


Fig. 5. L-Tryptophan concentrations in kale and kohlrabi sprouts (the groups marked with the same index differed significantly).
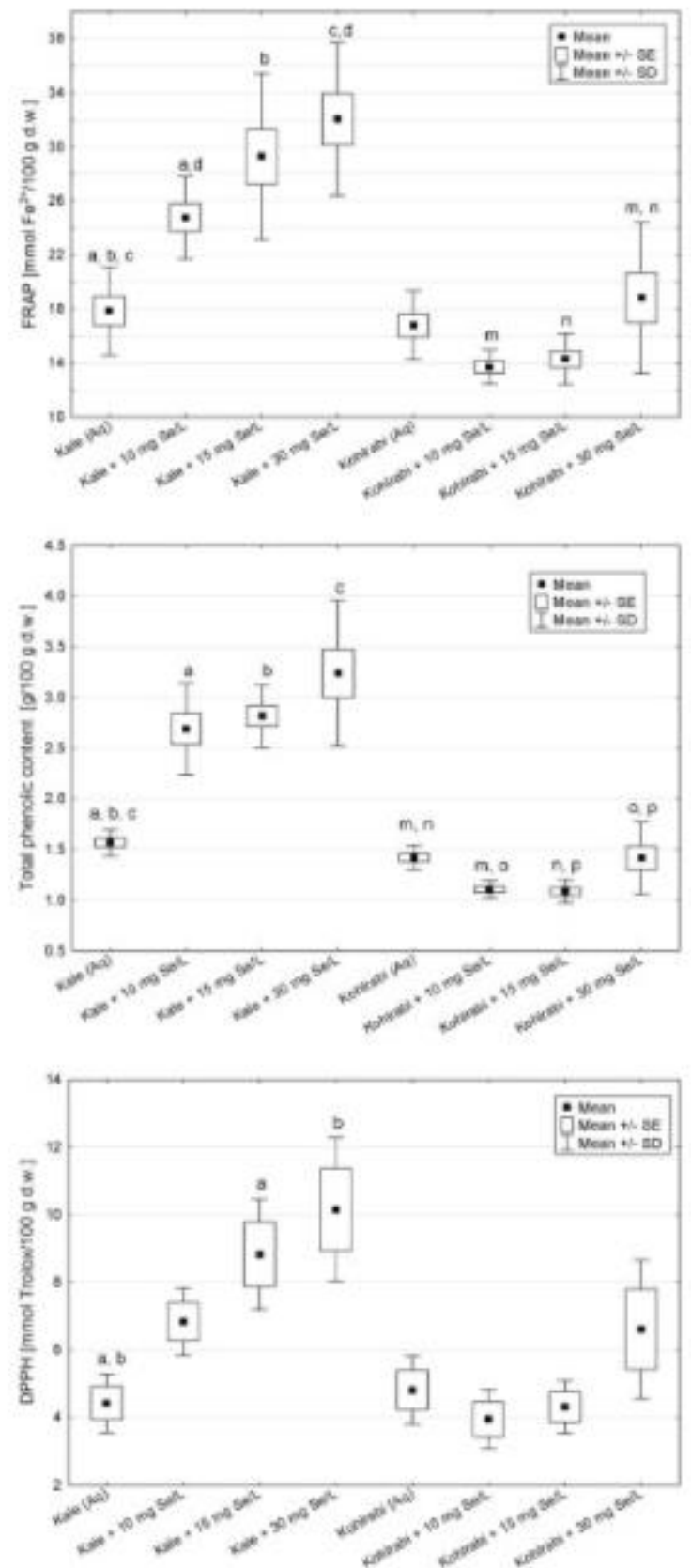

Fig. 6. Antioxidant parameters in kale and kohlrabi sprouts (the groups marked with the same index differed significantly; because of apparent difference between kale and kohlrabi sprouts, statistical tests were applied separately to both groups).

The highest content of sinapic acid was observed in kale sprouts fortified with 15 or $30 \mathrm{mg} / \mathrm{L}$ selenium (120.0 \pm 1.8 and $175.7 \pm 1.4 \mathrm{mg} / 100 \mathrm{~g} \mathrm{~d} . \mathrm{w}$. , respectively), while in most samples of kohlrabi sprouts the compound was not detected (Fig. 4A). Chlorogenic acid occurred solely in kale sprouts (for most of the samples being in the range between 4 and $9 \mathrm{mg} / 100 \mathrm{~g}$ d.w., respectively), and its highest concentration $(10.3 \pm 0.1 \mathrm{mg} / 100 \mathrm{~g} \mathrm{~d} . \mathrm{w}$.) was noted for the sample fortified with $30 \mathrm{mg} / \mathrm{L}$ selenium 
(Fig. 4B). Isochlorogenic acid was quantitatively determined only in Se-fortified sprouts of both tested species. Its content in kale sprouts was one order of magnitude higher, as compared with kohlrabi sprouts $(2349.8 \pm 448.1$ vs. $383.1 \pm 116.9 \mathrm{mg} / 100$ g d.w.). Moreover, isochlorogenic acid showed apparent dose dependent positive relationship with selenium in kale samples, however, without statistical significance (Fig. 4C). Caffeic acid content in almost all tested sprouts was of the same order of magnitude (mean values in the range 140-430 mg/100 d.w.), although with many detailed differences, and one exceptionally low amount in the case of unfortified kale sprouts $(15.7 \pm 7.1 \mathrm{mg} / 100 \mathrm{~g} \mathrm{~d}$.w.) (Fig. 4D). L-tryptophan content was one order of magnitude higher in Se-fortified kale than kohlrabi sprouts, among which no significant differences in the content of the compound was observed (Fig. 5). Fig. $\underline{6}$ shows the changes of the antioxidant parameters associated with the growing amounts of selenium used for the sprouts fortification.

PCA model constructed for all the above mentioned parameters had two significant components, according to cross-validation, and explained $87.5 \%$ of the variance in the original parameters, with eigenvalues equalled 6.36 and 1.52 for the first and the second component, respectively.The first principal component in this model had large positive weights for all parameters apart from selenium and caffeic acid. Other phenolic acids, antioxidant parameters and L-tryptophan formed cluster of - in most cases - highly correlated parameters. The correlation structure between the parameters in the PCA model was shown in Fig. 7A. The highest positive correlation weights based on the first principal component were revealed between TPC and both sinapic acid and FRAP, as well as between FRAP and isochlorogenic acid (Table 1). The second principal component was loaded positively by caffeic acid and selenium, and negatively by chlorogenic acid (Fig. 7A). Therefore caffeic acid had high, but opposed correlation weights with selenium and chlorogenic acid (Table 1). The correlations revealed by PCA method were confirmed also by Pearson correlation analysis, with an exception for the correlation between caffeic acid and selenium (Table 1). Fig. 7B shows the projection of the sprouts on the plane defined by the first two principal components of the PCA model. The sprouts formed four distinct clusters. The kohlrabi sprouts fortified with the highest dose of selenium (30 mg $\mathrm{Se} / \mathrm{L}$ ) deviated most from all the other sprouts. 
A

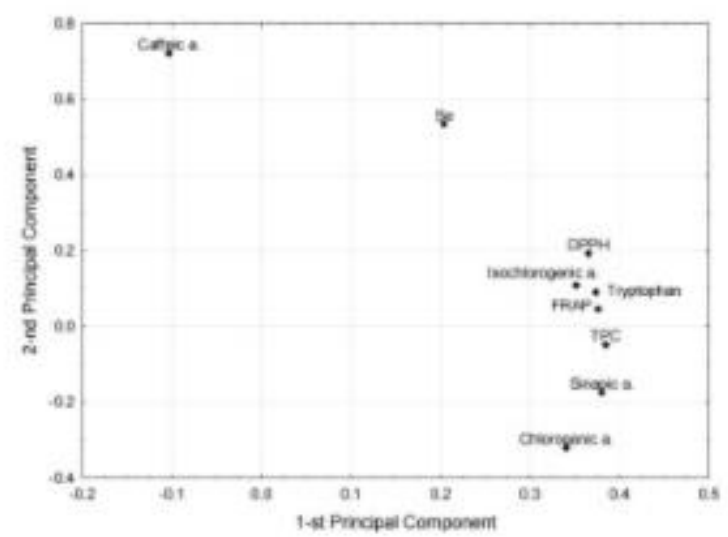

B

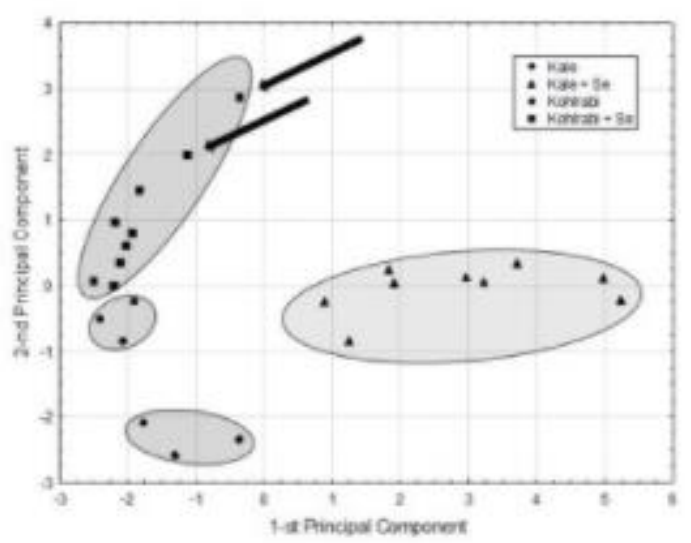

Fig. 7. PCA model evaluation. A: The weights of the first two components of PLS model; B: The projection of the sprouts on the plane defined by the first two principal components of the PCA model. The boundary lines of each cluster were depicted. The arrows indicate kohlrabi sprouts supplemented with $30 \mathrm{mg} \mathrm{Se} / \mathrm{L}$.

Table 1. Correlation weights (based on PCA model), and Pearson correlation coefficients for most significant bivariate associations (only correlation weights with absolute values bigger than 0.100 were shown).

\begin{tabular}{lll}
$\begin{array}{l}\text { Pairs of correlated } \\
\text { parameters }\end{array}$ & $\begin{array}{l}\text { Correlation weights } \\
\text { (PCA) }\end{array}$ & $\begin{array}{l}\text { Pearson correlation } \\
\text { significance }\end{array}$ \\
\hline Se and caffeic a. & 0.376 & $\mathrm{NS}$ \\
\hline Sinapic a. and TPC & 0.140 & $\mathrm{r}=0.926, \mathrm{p}<0.001$ \\
\hline FRAP and TPC & 0.140 & $\mathrm{r}=0.926, \mathrm{p}<0.001$ \\
\hline Isochlorogenic a. and FRAP & 0.140 & $\mathrm{r}=0.852, \mathrm{p}<0.001$ \\
\hline $\begin{array}{l}\text { Isochlorogenic a. and TPC } \\
\text { Isochlorogenic a. and DPPH }\end{array}$ & 0.134 & $\mathrm{r}=0.914, \mathrm{p}<0.001$ \\
\hline $\begin{array}{l}\text { Isochlorogenic a. and } \\
\text { tryptophan }\end{array}$ & 0.133 & $\mathrm{r}=0.837, \mathrm{p}<0.002$ \\
FRAP and tryptophan & 0.130 & $\mathrm{r}=0.816, \mathrm{p}<0.05$ \\
\hline
\end{tabular}



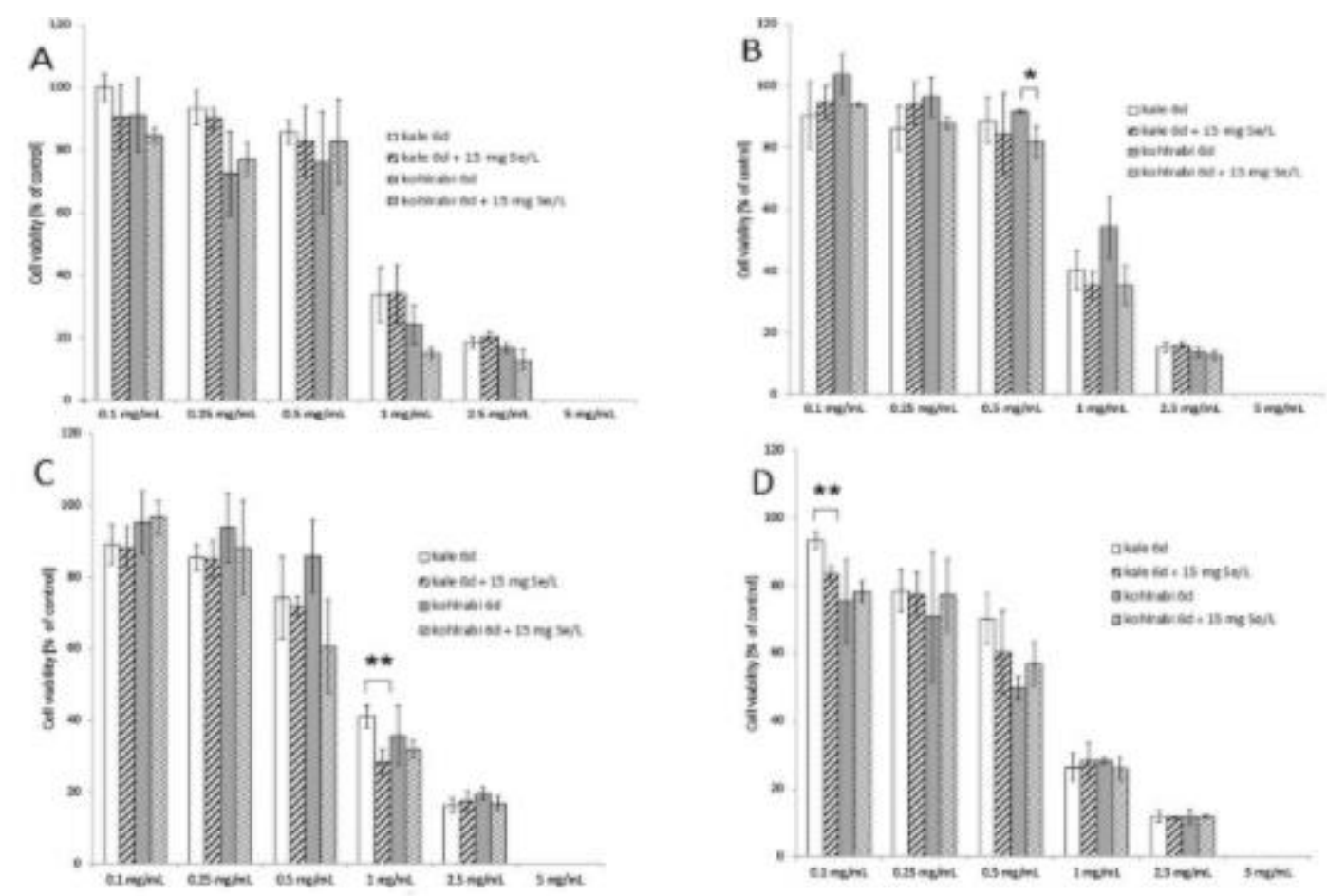

E
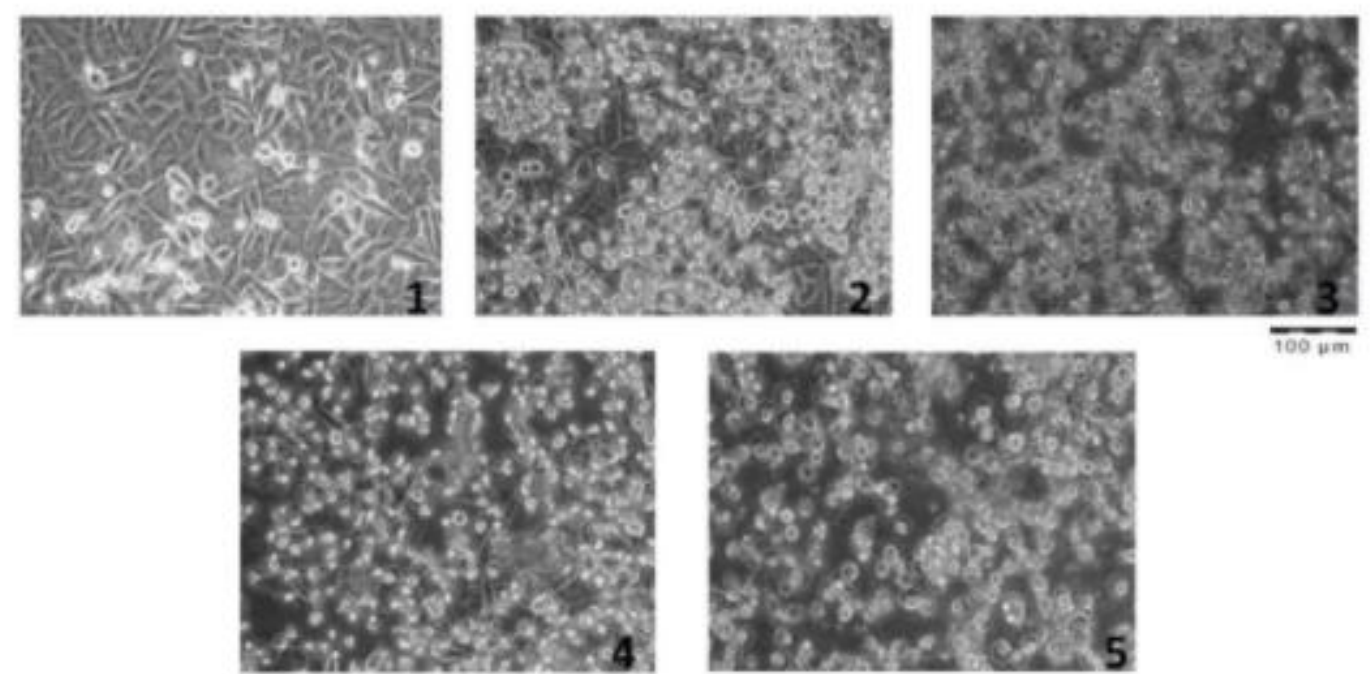

Fig. 8. Cytotoxic activity kale and kohlrabi sprouts extracts (*difference statistically significant) in colorectal adenocarcinoma SW480 (A), colorectal adenocarcinoma SW620 (B), hepatocellular carcinoma HepG2 (C), cervical carcinoma SiHa (D); (E): Phase contrast microphotographs of cervical carcinoma SiHa cell cultures. (1): untreated cells; (2): cells exposed to the extracts of kale; (3): cells exposed to the extracts of kale $+15 \mathrm{mg} \mathrm{Se} / \mathrm{L}$; (4): cells exposed to the extracts of kohlrabi; (5): cells exposed to the extracts of kohlrabi $+15 \mathrm{mg} \mathrm{Se} / \mathrm{L}$ (all the tested sprouts were grown for 6 days; the concentration of all the extracts was $1 \mathrm{mg} / \mathrm{mL}$ ).

\section{Discussion}


Selenium food fortification with i.e. SeMet, selenite and Se-yeast is a one of the possibilities to increase the amount of this trace element in daily nutrition [27]. Implementation of functional foods (also rich in Se) and searching for their new examples may offer health benefits and can get strong acceptance of consumers, hopefully leading to the change of their dietary habits [27,28]. Brassica crops and their sprouts are well-documented and often consumed example of chemopreventive food, but among them kohlrabi sprouts are not fully examined yet [ㄱ,2요. Brassica plants are also known from their high ability to accumulate some forms of Se, but the information on the influence of this trace element on the synthesis of secondary metabolites is still incomplete [7,23]. Thus, our study was designed to better comprehend the optimization of selenium plant treatment to obtain the products of increased nutritional and chemopreventive values and high safety. This aim was supported by the novel approach of PCA model-based comparison of the relationships between the evaluated parameters.

As we expected, Se-enriched sprouts proved to be more rich in this trace element when compared to the unfortified material, with the difference even several orders of magnitude higher (Fig. 1). The kale or kohlrabi sprouts fortified with the lowest dose of selenium can be classified as secondary Se accumulators (Se content 0.025$0.100 \mathrm{mg} / \mathrm{g} \mathrm{d} . \mathrm{w}$.), while the sprouts enriched with higher Se doses as primary accumulators (Se content $0.100-1.000 \mathrm{mg} / \mathrm{g}$ d.w.) [1]. Thus, apart from so far known sprouts of wheat or alfalfa that can accumulate selenium [29], the kale and kohlrabi sprouts also have the high ability to easily incorporate Se, which is an important and novel information. Different Brassica sprouts have varied capacity to accumulate selenium, with the lowest observed for Brussels sprouts, and higher for green cabbage, cauliflower and broccoli. The Se accumulation also depends on the cultivars, as significant variation among the sprouts of cauliflower, Chinese cabbage and kale cultivars was observed, ranging from $25 \%$ in cauliflower to 2.3 -fold difference in kale [7].

Several plants have been reported to accumulate and transform the inorganic forms of selenium into its bioactive organic compounds, present in commercially available products [30]. The SEC-ICP-MS profiles obtained for kale and kohlrabi sprouts were very similar (Fig. 2), with the presence of relatively low molecular weight (MW < $2000 \mathrm{Da}$ ) Se containing species, but no water soluble high molecular weight selenospecies. The selenium distribution seems to be the same in extracts of the control (untreated) and enriched samples, which suggests that no new species of Se were 
induced after the supplementation. In addition, the relatively low content of SeMet in the fortified material shows that Se may be incorporated into species other than proteins. However, future speciation studies are necessary to evaluate the exact composition of bioaccessible and bioavailable fractions of selenium in the tested sprouts. The analysis should also consider selenized species not extractable to the water fraction which, as it was mentioned before, can be expected in plant organisms $[31, \underline{32}]$. Although the aqueous extracts of both plants contained only traces of selenomethionine, its concentration was significantly higher after the proteolysis, which liberated this selenoaminoacid from the Se-containing proteins, while the intensity of Se-methylselenocysteine peaks was not affected by the proteolysis, and the content of this species remained at the same level in aqueous extracts and proteolytic digests of both plants (Fig. 3).

The retention times of the peaks eluting at the beginning of the chromatograms do not match those of commercially available standard species (Fig. 3). A dedicated study, beyond the scope of the current work, would be required to carry out comprehensive de novo identification of selenium species present in the studied material.

Avila et al. [7] noted that the sprouts of green cabbage cultivars and Brussels had low SeMSCys content (average 50-70 $\mu \mathrm{g} / \mathrm{g} \mathrm{d}$.w.) in comparison to the sprouts of the other Brassica crops, while Chinese cabbage accumulated relatively high (100-150 $\mu \mathrm{g} / \mathrm{g}$ d.w.) SeMSCys. In the sprouts of broccoli, green cabbage and cauliflower cultivars, similar level of SeMSCys was detected, while for the sprouts of Chinese cabbage and kale cultivars significant variation of SeMSCys level was noted [7]. SeMSCys was also the main selenium species in 28 sprouts species harvested in a high selenium environment. Moreover, in several of the evaluated sprouts, selenomethionine, non-metabolized selenite, $\gamma$-glutamyl-Se-methylselenocysteine and an unknown selenium compound were found [33]. In our experiment we obtained much lower concentrations of this selenoaminoacid. However, Seppänen et al. proved recently, that its concentrations depended strongly on the treatment of sprouts during their growth and might differ even by a few dozen factors [34].

Although selenium is not essential for plants, a number of beneficial effects of this element on plant physiology have been observed in many plant species [35]. Se can up-regulate plant enzymes (peroxidases and reductases) responsible for antioxidant protection [36]. Moreover, the plants supplemented with Se are also more resistant to other environmental stressors like ultraviolet radiation or heavy metal 
contamination [37]. However, the role Se plays in plant physiology, strongly depends on both its concentration and plant tolerance [35]. This implies the question about the interaction between Se and other, potentially beneficial compounds (secondary metabolites) present in plant organisms. To answer this question, in our experiment we focused on the quantitative analysis of phenolic acids and L-tryptophan. Sinapic and chlorogenic acids were detected only in kale sprouts, both untreated and Sefortified. While sinapic acid amount increased proportional to the selenium doses used for the fortification (Fig. 4A), chlorogenic acid content differed only between the untreated samples and the ones fortified with the highest Se dose (Fig. 4B).

Isochlorogenic acid was present only in Se-fortified kale and kohlrabi sprouts, but in much lower amount in the latter species (Fig. 4C). The tendency of increasing caffeic acid content in the samples treated with higher doses of selenium was observed only for kohlrabi sprouts (Fig. 4D). Thus, selenium differentially affected the production of the analysed phenolic acids, depending on the particular sprout species and Se dose but generally caused the increase in the content of these compounds, with subsequent progression of antioxidant activities in kale sprouts (Fig. 6). The general routes of possible selenium influence on plant phenolic compounds were recently reviewed by Chomchan et al. [38] and our results seem to be consistent with the conclusions of this review. We have proved that low selenium concentrations generally stimulated phenolic acids production in the tested sprouts, apparently acting similar to light stressor, however the exact mechanisms should be clarified in the future.

Apart from polyphenolic compounds, Brassica vegetables and their sprouts can be also an important source of indole derivates [4]. Tryptophan as a serotonin precursor may affect depression and mood scores of healthy participants [4]. In our experiment we have observed that selenium fortification induced significant, but not dosedependent, increase in L-tryptophan content in kale sprouts (Fig. 5), with no effect for kohlrabi sprouts. Our experiment is probably the first to demonstrate the impact of Se fortification of L-tryptophan synthesis in any Brassica sprouts, but further studies are needed to explain the observed differences between the species.

As Brassica vegetables and sprouts are known from their antioxidant properties [18], in the next step of our experiment we determined if Se fortification may influence the total phenolic content (TPC) and antioxidant parameters (FRAP, DPPH) of the tested sprouts. The obtained results followed the same pattern of changes as we have noted for phenolic acids analysis. Steady increase with the increasing Se doses for 
kale sprouts, and no such trend, or even lower results for intermediate Se doses, were observed for kohlrabi sprouts (Fig. 6). It suggests that kale sprouts are more vulnerable to Se-stimulated higher antioxidant activity, in comparison to kohlrabi sprouts. On the other hand, it can be interpreted as greater ability of kohlrabi sprouts to equilibrate changing Se status as homeostatic phenomena [1]. Similar positive impact of low selenium dose $(10 \mathrm{mg} / \mathrm{L})$ on TPC content was found for $A$. cruentus and A. tricolor sprouts, with the opposite effect for A. caudatus sprouts. A higher selenium dose (15 mg Se/L) caused insignificant increase in TPC in amaranth sprouts, in comparison to the sprouts treated with $10 \mathrm{mg} \mathrm{Se} / \mathrm{L}$. Moreover, significant increase in antioxidant activity was observed for selenium fortified $A$. cruentus sprouts. For the other two evaluated amaranth cultivars, the antioxidant activity either did not change, or decreased strongly, in response to $15 \mathrm{mg} \mathrm{Se} / \mathrm{L}$ water dose (A. tricolor) [23]. No clear relation between the selenium concentration and antioxidant activity (FRAP, DPPH) of kale and kohlrabi sprouts was found, however Djanaguiraman et al. noted that the increase in the antioxidant activity was positively correlated with the Se content in the plants [39].

To better interpret the relationships between the obtained results we involved PCA, an approach which has not been applied to the analysis of kale or kohlrabi sprouts so far. The applied PCA model revealed correlation structure between the investigated parameters. Among phenolic acids only caffeic acid was not strongly correlated with other secondary metabolites, but it correlated with selenium (Fig. 7A, Table 1). This may suggest particular selenium dependence of the enzymes catalyzing metabolic changes of caffeic acid, and should be clarified in future studies.

Four distinct clusters formed by the sprouts on the plane defined by the first two principal components of the PCA model reflected different species and treatment (fortification of Se or its lack). This means that PCA model was effective enough to differentiate between the examined groups of the sprouts (Fig. 7B) and to indicate the sprouts deviating most from the others. In our previous papers PCA model was also applied $[23, \underline{40]}$ and proved to be an useful tool in relevant description of the relationships among parameters being investigated.

Finally, we examined the cytotoxic properties of selenium treated and untreated kale and kohlrabi sprouts, to answer the question on their possible chemopreventive potential. In our experiments we used a panel of four human cancer cell lines (SW480, SW620, HepG2, SiHa) of different tissue origin, to determine multidirectional effect of the tested extracts. Moreover, two of the chosen colorectal adenocarcinomas also 
differed in the stage of tumorigenesis and the degree of invasion. The tested sprout extracts exerted varied cytotoxicity towards the cancer cells at concentration 1.0 $\mathrm{mg} / \mathrm{mL}$ and higher (Fig. 8). Interesting differences in the impact of untreated kale and kohlrabi sprouts on primary (SW480) and metastatic (SW620) colorectal adenocarcinoma cells were also noted, with more profound effect of kale sprouts on the latter cell line. Other Brassica sprouts (broccoli, rutabaga) revealed selective cytotoxic activity against different human cancer cell lines (HepG2, SW480) with no significant effect on normal cells $[40,41]$. In comparison to these results, the tested kale and kohlrabi sprouts at the concentration of $1 \mathrm{mg} / \mathrm{mL}$ had significantly higher cytotoxic activity against HepG2 and SW480 cells. In our previous study on selenium treated $(15 \mathrm{mg} / \mathrm{mL}$ ) amaranth sprouts (A. cruentus, A. caudatus, A. tricolor) no significant difference in the cytotoxic activity between the treated and controlled sprouts on RAW 264.7 cells was observed, which is consisted with the presented results [23].

\section{Conclusions}

Our results indicate that Se enrichment is an interesting and perspective idea for plant functional foods industry in the future. The addition of selenium stimulated the production of some phytochemical compounds in different ways, depending on the particular sprout species, selenium dose and the investigated compound. As selenium correlated only with caffeic acid, and other parameters (DPPH, FRAP, TPC, phenolic acids and L-tryptophan) were strongly intercorrelated, the detailed mechanisms of selenium action should be clarified in future studies. The obtained results also proved that the tested sprouts induced significant decrease in the viability of SW480 and SW620 colorectal adenocarcinoma cells, differing in metastatic potential. This may have some future implications for the use of selenium-fortified or unfortified kale and kohrabi sprouts in the chemoprevention of colon cancer. Moreover, we did not observed any negative influence of Se on the content of the investigated active compounds. Thus, Se-fortified kale and kohlrabi sprouts may become potentially attractive and safe ingredients of functional food.

\section{Author's statement}

Pawel Zagrodzki: Conceptualization, Methodology, Formal analysis, WritingOriginal draft preparation, Visualization, Writing- Reviewing and Editing, Funding 
acquisition Paweł Paśko: Conceptualization, Methodology, Resources, WritingOriginal draft preparation, Visualization, Writing- Reviewing and Editing, Investigation, Project administration Agnieszka Galanty: Methodology, WritingReviewing and Editing, Data Curation, Investigation Malgorzata Tyszka-

Czochara: Methodology, Investigation Renata Wietecha-

Posłuszny: Methodology, Investigation Pol Salvans Rubió: Investigation Henryk

Bartoń: Methodology Ewelina Prochownik: Investigation Bożena

Muszyńska: Methodology, Resources Katarzyna Sułkowska-

Ziaja: Investigation Katarzyna Bierla: Investigation Ryszard

Lobiński: Resources, Supervision Joanna Szpunar: Resources, Methodology,

Writing- Reviewing and Editing, Data Curation, Investigation Shela

Gorinstein: Supervision.

\section{Declaration of Competing Interest}

Not exist.

\section{Acknowledgement}

This work was partially supported within Israel Academy of Sciences and Humanities (IASH) - Polish Academy of Sciences (PAN) Agreement on Scientific Cooperation and by grants from the Polish Ministry of Science and Higher Education: K/ZDS/006228, K/ZDS/007965, K/DSC/005333, K/ZDS/007076 and Nㅡㄴ 42/DBS/000111.

\section{Appendix A. Supplementary data}

The following is Supplementary data to this article: Download : Download zip file (341B)

\section{References}

\section{$[1]$}

R. Chomchan, S. Siripongvutikorn, P. Puttarak, R. Rattanapon

Influence of selenium bio-fortification on nutritional compositions, bioactive compounds content and anti-oxidative properties of young rice grass (Oryza sativa $\mathrm{L}$.)

FFHD, 7 (2017), pp. 195-209, 10.31989/ffhd.v7i3.321

$[2]$

H. Olsen, K. Aaby, G.I.A. Borge 
Characterization and quantification of flavonoids and hydroxycinnamic acids in curly kale (Brassica oleracea L. convar. acephala var. sabellica) by HPLC-DAD-ESI-MS n J. Agric. Food Chem., 57 (7) (2009), pp. 2816-2825, 10.1021/jf803693t

\section{$[3]$}

A.L.H. Steindal, R. Rødven, E. Hansen, J. Mølmann

Effects of photoperiod, growth temperature and cold acclimatisation on glucosinolates, sugars and fatty acids in kale

Food Chem., 174 (2015), pp. 44-51, 10.1016/j.foodchem.2014.10.129

\section{$[4]$}

P. Pasko, K. Sulkowska-Ziaja, B. Muszynska, P. Zagrodzki

Serotonin, melatonin, and certain indole derivatives profiles in rutabaga and kohlrabi seeds, sprouts, bulbs, and roots

LWT-Food Sci. Technol., 59 (2) (2014), pp. 740-745, 10.1016/j.1wt.2014.07.024

\section{$[5]$}

G. Alfthan, M. Eurola, P. Ekholm, E.R. Venäläinen, T. Root, K. Korkalainen, H. Hartikainen, P. Salminen, V. Hietaniemi, A. Aro

Effects of nationwide addition of selenium to fertilizers on foods, and animal and human health in Finland: from deficiency to optimal selenium status of the population

J. Trace Elem. Med. Biol., 31 (2015), pp. 142-147, 10.1016/j.jtemb.2014.04.009

\section{$[6]$}

M. Wiesner-

Reinhold, M. Schreiner, S. Baldermann, D. Schwarz, F.S. Hanschen, A.P. Kipp, D.D. Rowan, K.L. Bentley-Hewitt, M.J. McKenzie

Mechanisms of selenium enrichment and measurement in Brassicaceous vegetables, and their application to human health

Front. Plant Sci., 8 (2017), p. 1365, 10.3389/fpls.2017.01365

\section{$[7]$}

F.W. Ávila, Y. Yang, V. Faquin, S.J. Ramos, L.R.G. Guilherme, T.W. Thannhauser, L. Li Impact of selenium supply on Se-methylselenocysteine and glucosinolate accumulation in selenium-biofortified Brassica sprouts

Food Chem., 165 (2014), pp. 578-586, 10.1016/j.foodchem.2014.05.134

\section{$[8]$}

R. Abdulah, H. Koyama, A. Faried, K. Kobayashi, C. Yamazaki, E.W. Suradji, K. Ito, K. Suz uki, M. Murakami, H. Kuwano, H. Koyama

Selenium enrichment of broccoli sprout extract increases chemosensitivity and apoptosis of LNCaP prostate cancer cells

BMC Cancer, 9 (1) (2009), p. 414, 10.1186/1471-2407-9-414

$[9]$

J.W. Finley

Proposed criteria for assessing the efficacy of cancer reduction by plant foods enriched in carotenoids, glucosinolates, polyphenols and selenocompounds

Ann. Bot., 95 (7) (2005), pp. 1075-1096, 10.1093/aob/mci123 
$[10]$

X. Yao, J. Chu, G. Wang

Effects of selenium on wheat seedlings under drought stress

Biol. Trace Elem. Res., 130 (2009), pp. 283-290, 10.1007/s12011-009-8328-7

\section{$[11]$}

C.C. Chen, J.M. Sung

Priming bitter gourd seeds with selenium solution enhances germinability and antioxidative responses under sub-optimal temperature

Physiol. Plant., 111 (2001), pp. 9-16, 10.1034/j.1399-3054.2001.1110102.x

\section{$[12]$}

X. Yao, J. Chu, C. Ba

Antioxidant responses of wheat seedlings to exogenous selenium supply under enhanced Ultraviolet-B

Biol. Trace Elem. Res., 136 (2010), pp. 96-105, 10.1007/s12011-009-8520-9

\section{$[13]$}

M. Hasanuzzaman, M.A. Hossain, M. Fujita

Selenium-induced up-regulation of the antioxidant defense and methylglyoxal detoxification system reduces salinity-induced damage in rapeseed seedlings Biol. Trace Elem. Res., 143 (2011), pp. 1704-1721, 10.1007/s12011-011-8958-4 CrossRefView Record in ScopusGoogle Scholar

\section{[14]}

M.P. Rayman

The importance of selenium to human health

Lancet, 356 (9225) (2000), pp. 233-241, 10.1016/S0140-6736(00)02490-9

\section{$[15]$}

M. Tyszka-Czochara, P. Paśko, P. Zagrodzki, E. Gajdzik, R. WietechaPosluszny, S. Gorinstein

Selenium supplementation of amaranth sprouts influences betacyanin content and improves anti-inflammatory properties via NFKB in murine RAW 264.7 macrophage Biol. Trace Elem. Res., 169 (2016), pp. 320-330, 10.1007/s12011-015-0429-X

\section{[16]}

P. Zagrodzki, R. Ratajczak, R. Wietecha-Posluszny

The interaction between selenium status, sex hormones, and thyroid metabolism in adolescent girls in the luteal phase of their menstrual cycle

Biol. Trace Elem. Res., 120 (2007), pp. 51-60, 10.1007/s12011-007-8012-8

\section{$[17]$}

K. Bierła, N. Suzuki, Y. Ogra, J. Szpunar, R. Łobiński

Identification and determination of selenohomolanthionine - the major selenium compound in Torula yeast

Food Chem., 237 (2017), pp. 1196-1201, 10.1016/j.foodchem.2017.06.042

$[18]$

P. Paśko, A. Galanty, P. Żmudzki, J. Gdula-Argasińska, P. Zagrodzki 
Influence of different light conditions and time of sprouting on harmful and beneficial aspects of rutabaga sprouts in comparison to their roots and seeds

J. Sci. Food Agric., 99 (1) (2019), pp. 302-308, 10.1002/jsfa.9188

\section{[19]}

B. Muszyńska, J. Piotrowska, A. Krakowska, A. Gruba, K. Kała, K. Sułkowska-

Ziaja, A. Kryczyk, W. Opoka

Study of physiologically active components in different parts of fruiting bodies of varieties of Agaricus bisporus (white mushroom)

Eur. Food Res. Technol., 243 (2017), pp. 2135-2145, 10.1007/s00217-017-2914-2

\section{$[20]$}

B. Muszyńska, K. Sułkowska-Ziaja, H. Ekiert

Indole compounds in fruiting bodies of some selected Macromycetes species and in their mycelia cultured in vitro

Pharmazie, 64 (2009), pp. 479-480, 10.1691/ph.2008.8727

\section{[21]}

K. Sułkowska-Ziaja, A. Szewczyk, A. Galanty, J. Gdula-Argasińska, B. Muszyńska Chemical composition and biological activity of extracts from fruiting bodies and mycelial cultures of Fomitopsis betulina

Mol. Biol. Rep., 45 (2018), pp. 2535-2544, 10.1007/s11033-018-4420-4

[22]

W. Brand-Williams, M.E. Cuvelier, C. Berset

Use of a free radical method to evaluate antioxidant activity

LWT - Food Sci. Technol., 28 (1995), pp. 25-30, 10.1016/S0023-6438(95)80008-5

[23]

P. Paśko, J. Gdula-Argasinska, J. Podporska-Carroll, B. Quilty, R. Wietecha-

Posluszny, M. Tyszka-Czochara, P. Zagrodzki

Influence of selenium supplementation on fatty acids profile and biological activity of four edible amaranth sprouts as new kind of functional food

J. Food Sci. Technol., 52 (2015), pp. 4724-4736, 10.1007/s13197-014-1602-5

\section{[24]}

I.F. Benzie, J.J. Strain

The ferric reducing ability of plasma (FRAP) as a measure of "antioxidant power": the FRAP assay

Anal. Biochem., 239 (1996), pp. 70-76, 10.1006/abio.1996.0292

\section{$[25]$}

M. Tyszka-Czochara, K. Bukowska-Strakova, K.A. Kocemba-Pilarczyk, M. Majka

Caffeic acid targets AMPK signaling and regulates tricarboxylic acid cycle anaplerosis while metformin downregulates HIF-1 $\alpha$-induced glycolytic enzymes in human cervical squamous cell carcinoma lines

Nutrients, 10 (2018), pp. 1-21, 10.3390/nu10070841

$[26]$

M. Tyszka-Czochara, K. Bukowska-Strakova, M. Majka 
Metformin and caffeic acid regulate metabolic reprogramming in human cervical carcinoma $\mathrm{SiHa} / \mathrm{SIHA} / \mathrm{HTB}-35$ cells and augment anticancer activity of Cisplatin via cell cycle regulation

Food Chem. Toxicol., 106 (Pt. A) (2017), pp. 260-272, 10.1016/j.fct.2017.05.065

\section{[27]}

D.N. Cox, K. Bastiaans

Understanding Australian consumers' perceptions of selenium and motivations to consume selenium enriched foods

Food Qual. Prefer., 18 (1) (2007), pp. 66-76, 10.1016/j.foodqual.2005.07.015

\section{$[28]$}

J.W. Finley

Reduction of cancer risk by consumption of selenium-enriched plants: enrichment of broccoli with selenium increases the anticarcinogenic properties of broccoli

J. Med. Food, 6 (1) (2003), pp. 19-26, 10.1089/109662003765184714

\section{$[29]$}

J. Lintschinger, N. Fuchs, J. Moser, D. Kuehnelt, W. Goessler

Selenium-enriched sprouts. A raw material for fortified cereal-based diets

J. Agric. Food Chem., 48 (2000), pp. 5362-5368, 10.1021/jf000509d

\section{[30]}

K. Pyrzynska

Selenium speciation in enriched vegetables

Food Chem., 114 (2009), pp. 1183-1191, 10.1016/j.foodchem.2008.11.026

\section{[31]}

P.D. Whanger

Selenium and its relationship to cancer: an update

Br. J. Nutr., 91 (2004), pp. 11-28, 10.1079/BJN20031015

\section{$[32]$}

E. Dumont, F. Vanhaecke, R. Cornelis

Selenium speciation from food source to metabolites: a critical review

Anal. Bioanal. Chem., 385 (2006), pp. 1304-1323, 10.1007/s00216-006-0529-8

\section{[33]}

S. Sugihara, M. Kondo, Y. Chihara, M. Yuji, H. Hattori, M. Yoshida

Preparation of selenium-enriched sprouts and identification of their selenium species by high-performance liquid chromatography-inductively coupled plasma mass spectrometry

Biosci. Biotechnol. Biochem., 68 (1) (2004), pp. 193-199, 10.1271/bbb.68.193

\section{$[34]$}

M.M. Seppänen, N. Ebrahimi, J. Kontturi, H. Hartikainen, I. Lopez

Heras, C. Cámara, Y. Madrid

Dynamics of selenium uptake and metabolism of organic selenium species in the leaves and seeds of Brassica napus $\mathrm{L}$ 
Agric. Food Sci., 27 (2018), pp. 38-49, 10.23986/afsci.67837

$[35]$

M. Schiavon, E.A. Pilon-Smits

The fascinating facets of plant selenium accumulation - biochemistry, physiology, evolution and ecology

New Phytol., 213 (2017), pp. 1582-1596, 10.1111/nph.14378

\section{[36]}

E.A.H. Pilon-Smits, C.F. Quinn, W. Tapken, M. Malagoli, M. Schiavon Physiological functions of beneficial elements

Curr. Opin. Plant Biol., 12 (2009), pp. 267-274, 10.1016/j.pbi.2009.04.009

[37]

R. Feng, C. Wei, S. Tu

The roles of selenium in protecting plants against abiotic stresses

Environ. Exp. Bot., 87 (2013), pp. 58-68, 10.1016/j.envexpbot.2012.09.002

\section{[38]}

R. Chomchan, S. Siripongvutikorn, P. Maliyam, P. Puttarak

Selenium bio-fortification: an alternative to improve phytochemicals and bioactivities of plant foods

FFHD, 7 (2017), pp. 263-279, 10.31989/ffhd.v7i4.323

\section{$[39]$}

M. Djanaguiraman, D.D. Devi, A.K. Shanker, J.A. Sheeba, U. Bangarusamy

Selenium - an antioxidative protectant in soybean during senescence

Plant Soil, 272 (2005), pp. 77-86, 10.1007/s11104-004-4039-1

\section{$[40]$}

P. Paśko, M. Tyszka-Czochara, A. Galanty, J. Gdula-

Argasińska, P. Żmudzki, H. Bartoń, P. Zagrodzki, S. Gorinstein

Comparative study of predominant phytochemical compounds and proapoptotic potential of broccoli sprouts and florets

Plant Foods Hum. Nutr., 73 (2) (2018), pp. 95-100, 10.1007/s11130-018-0665-2

[41]

P. Paśko, K. Bukowska-Strakova, J. Gdula-Argasińska, M. Tyszka-Czochara

Rutabaga (Brassica napus L. var. napobrassica) seeds, roots, and sprouts: a novel kind of food with antioxidant properties and proapoptotic potential in Hep G2 hepatoma cell line

J. Med. Food, 16 (8) (2013), pp. 749-759, 10.1089/jmf.2012.0250 